\title{
IMPLANTE COCLEAR
}

\author{
COCHLEAR IMPLANT
}

José Antonio A. de Oliveira

Docente. Divisão de Otorrinolaringologia. Departamento de Oftalmologia, Otorrinolaringologia e Cirurgia de Cabeça e Pescoço. Faculdade de Medicina de Ribeirão Preto - USP.

CorRespondÊnCIA: Avenida Bandeirantes, 3900. Campus Universitário - Monte Alegre. 14.048-900 - Ribeirão Preto - SP.

Fone: (16) 3602-2863 - Fax: (16) 3602-2860, jaadoliv@fmrp.usp.br

Oliveira JAA. Implante coclear. Medicina (Ribeirão Preto) 2005, 38 (3/4): 262-272.

RESUMO: Atualmente, a cirurgia de implante coclear é o único tratamento eficaz em casos de surdez profunda bilateral em crianças e adultos. É importante fazer o diagnóstico da surdez sensorioneural através de uma bateria de exames especializados. Nesta avaliação há participação de uma equipe multidisciplinar. Com a avaliação realizada e os resultados obtidos e levando-se em conta os critérios de indicação para o implante, o paciente é selecionado para ser submetido à cirurgia de implantação. Nesta revisão a intenção foi focalizar o estado atual do tratamento da surdez profunda sensorioneural bilateral pela cirurgia de implante coclear.

Descritores: Implantes Cocleares. Perda Auditiva Neurossensorial. Orelha Interna. Labirinto.

\section{1- INTRODUÇÃO}

Várias são as causas de lesão das células ciliadas auditivas: trauma craniencefálico, doenças genéticas, drogas ototóxicas, ruído intenso, hipóxia, surdez súbita, labirintite infecciosa, viral, meningite, rubéola, icterícia neonatal e outras.

Estas agressões podem danificar as células ciliadas auditivas na cóclea. A cóclea que faz parte do labirinto ou orelha interna é que transforma as ondas de pressão acústica em estímulos neurais a partir das células ciliadas auditivas. Quando ocorre lesões em grande número de células ciliadas o resultado é uma disacusia sensorioneural que pode chegar a uma surdez profunda.

A causa mais comum de surdez é justamente aquela na qual ocorre a perda das células ciliadas mais do que neurônios auditivos. Neste caso, os neurônios remanescentes numa surdez sensorioneural profunda podem ser excitados diretamente por estimulação elétrica.
Como se sabe, qualquer tipo de estimulação nas vias nervosas dos órgãos sensoriais é percebida pelo córtex cerebral como sensação do órgão sensorial específico. Com base neste princípio fisiológico, as pesquisas se desenvolveram no sentido de substituir o mecanismo de audição normal provocando estimulação elétrica direta nos neurônios auditivos ganglionares remanescentes dentro do modíolo da cóclea (Figura 1). O desafio foi descobrir como estimular eletricamente os neurônios auditivos (células ganglionares do modíolo) de modo que informação significativa sobre a fala fosse transmitida ao cérebro como informação de amplitude e freqüência.

Sabe-se que a membrana basilar na orelha interna (cóclea) analisa o sinal de entrada em diferentes freqüências (teoria das ondas viajantes). A cóclea atua como analisador do espectro decompondo sons complexos em suas frequiências componentes.

A partir de 1960 foram realizadas as primeiras tentativas para restaurar a audição do surdo profundo com estimulação elétrica do nervo auditivo. Atualmente, 


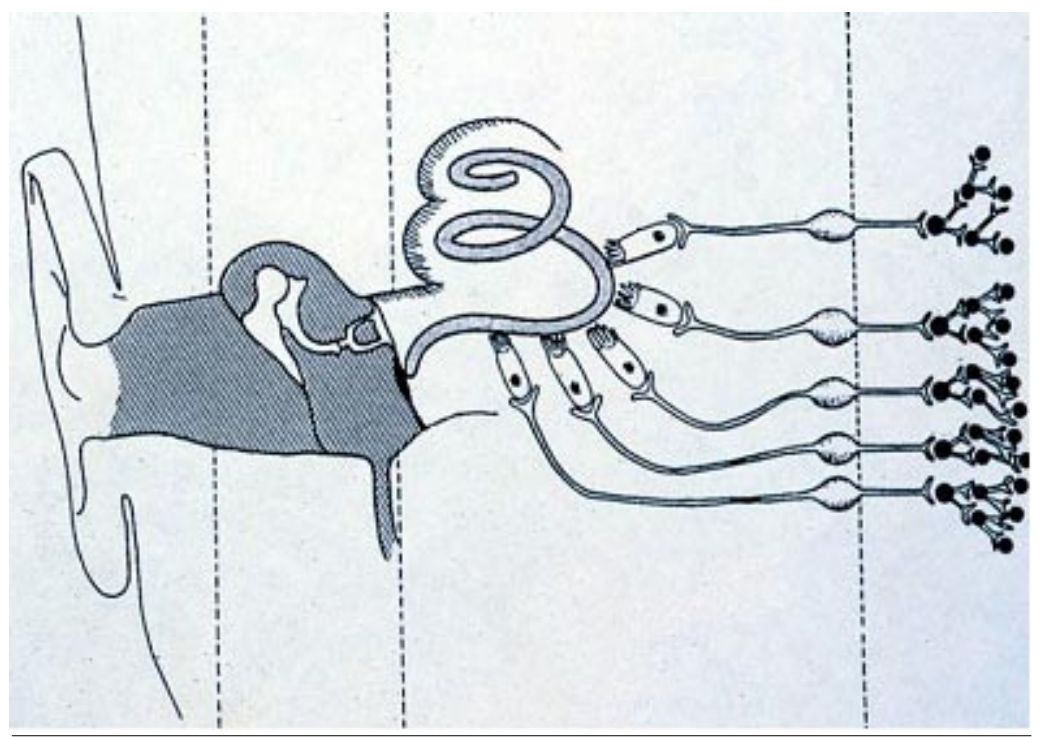

Figura 1 - Esquema mostrando a cóclea e as células ciliadas auditivas e neurônios ganglionares.

\section{1- Processador de sinal}

Transforma o sinal sonoro em diferentes frequiências enviando os sinais filtrados aos eletrodos apropriados. A importante função do processador é decompor o sinal de entrada em suas freqüências componentes como faz a cóclea normal. Este é o grande desafio do implante coclear; desenvolver técnicas de processamento de sinais como o realizado pela cóclea normal. A premissa é que devem existir fibras nervosas auditivas remanescentes suficientes na vizinhança dos eletrodos para haver estimulação. As fibras nervosas estimuladas deflagram e propagam impulsos neurais ao córtex cerebral na área auditiva do lado temporal.

O implante coclear transmite efe-

o implante coclear (I.C.) na orelha interna pode restaurar parcialmente a audição de pessoa com surdez profunda.

O dispositivo eletrônico usado como implante possibilita comunicação sem leitura labial ou sinais e, às vezes, até através do telefone.

\section{2- CARACTERÍSTICAS DOS IM- PLANTES COCLEARES}

Os elementos comuns de um implante coclear são: microfone, processador de sinal, sistema de transmissão, eletrodo único ou múltiplos (Figura 2). O chamado eletrodo monocanal já foi abandonado hoje, sendo utilizado apenas os multicanais.

Este conjunto de eletrodos é inserido na cóclea e diferentes fibras do nervo auditivo são estimuladas em diferentes locais explorando o place mechanism de codificação de freqüências (discriminação). Diferentes eletrodos são estimulados dependendo da freqüência do sinal. Eletrodos da base da cóclea correspondem aos sinais de alta freqüência, eletrodos do ápice correspondem a sinais de baixa freqüência.

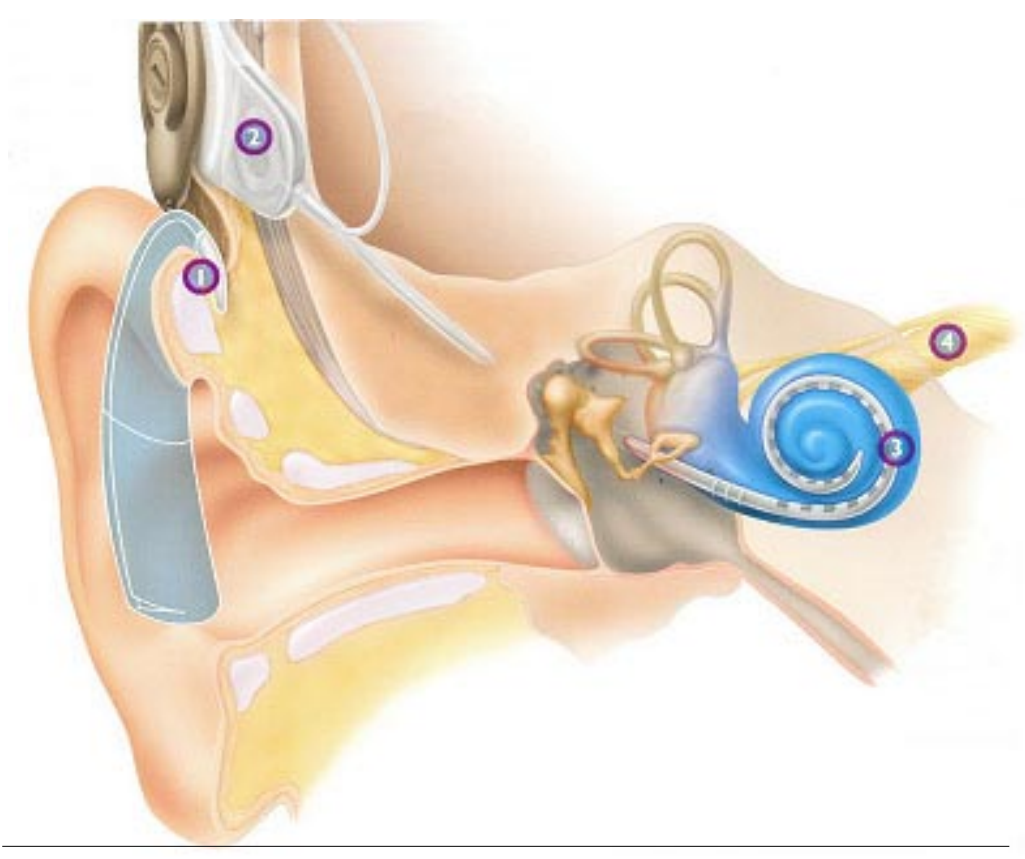

Figura 2 - Componentes externos do implante coclear. 1) Microfone e processador da fala (captura sons do meio e os converte em sinais digitais. O processador manda sinais digitais para os componentes internos, através de uma bobina (receptora externa); 2) bobina interna e o implante que fica sob a pele, num nicho fresado no osso temporal; 3) fio com eletrodos (anéis) do implante dentro da cóclea. Converte os sinais digitais do processador em energia elétrica; 4) eletrodos estimulam o nervo auditivo enviando sinais ao cérebro para a audição. 


\section{2- Percepção de intensidade e freqüência do som}

Intensidade - depende do número de fibras ativadas e suas frequiências de impulsos nervosos. Quando muitas fibras são ativadas, a sensação é de um som intenso. Esta percepção de intensidade do som pode ser controlada variando a amplitude de corrente estimulante.

Frequiência - depende do local da cóclea que é estimulado. As sensações de frequiências baixas (graves) são provocadas quando eletrodos perto do ápice são estimulados, sensações de freqüências altas (agudos) são provocadas pela estimulação de eletrodos próximos às regiões basais da cóclea.

\section{3- Funcionamento dos eletrodos}

Depende do projeto do eletrodo, ou seja, do número de eletrodos e de sua configuração. $\mathrm{O}$ tipo de estimulação pode ser analógico ou pulsátil. A ligação da transmissão pode ser transcutânea ou percutânea.

O processamento do sinal é responsável pela representação da forma da onda.

\section{4- Eletrodos e sua colocação}

O número de contatos é importante, bem como, a sua configuração e a sua orientação com relação aos tecidos excitáveis.

A colocação atual é na escala timpânica da cóclea (intracoclear) ou na superfície do núcleo coclear (tronco cerebral). A mais comum é a intracoclear, com proximidade máxima com os neurônios auditivos que ficam ao longo do comprimento do modíolo da cóclea. Esta colocação, neste nível, preserva o mecanismo de localização da codificação de frequiências da cóclea normal (tonotopia). O conjunto de eletrodos pode ser inserido na escala timpânica até $22-23 \mathrm{~mm}$ de comprimento.

\section{5- Tipos de estimulação}

Estimulação analógica - um análogo elétrico da forma da onda acústica é apresentado ao eletrodo. Nos eletrodos multicanais, a forma da onda acústica é filtrada, sendo esta apresentada a todos eletrodos simultaneamente. A vantagem desta estimulação é que o sistema nervoso faz uso de toda a informação contida nas formas de ondas acústicas. A desvantagem é que a ação simultânea pode causar interação entre os diferentes eletrodos.

Estimulação pulsátil - a informação é liberada aos eletrodos usando um conjunto estreito de pulsos.
Há a vantagem de os pulsos serem liberados de um modo não simultâneo, minimizando, então, as interações dos eletrodos. Taxas altas de pulsos permitem melhor desempenho do que taxas baixas.

\section{6- Transmissão de sinais}

transcutânea - a transmissão dos sinais do processador aos eletrodos implantados pode ocorrer por via transcutânea, quando o transmissor externo codifica a informação (estímulo) e esta, por radiofrequiência é transmitida de uma bobina externa a uma bobina interna implantada e colocada num leito construído na parede óssea craniana, no osso temporal. O sinal que é decodificado vai para os eletrodos para estimulação das fibras nervosas. O contato das bobinas externas com a interna - receptor-estimulador - é realizado por dispositivo magnético.

Este tipo de transmissão é o mais usado nos implantes atualmente. A maioria dos implantes (Nucleus ${ }^{\circledR}$, Clarion ${ }^{\circledR}$, MED-EL $®$ ) tem esse tipo de transmissão. A vantagem desta transmissão transcutânea é que a pele após a cirurgia é fechada evitando infecção. A desvantagem é que, ocorrendo falha nos dispositivos, pode haver necessidade de outra cirurgia. Outra desvantagem é a presença de material magnético que é incompatível com a realização de exames de ressonância magnética;

transmissão percutânea - 0 estímulo é transmitido aos eletrodos diretamente através da conexão com plugue, sendo somente os eletrodos implantados.

A vantagem desta transmissão é a flexibilidade e transparência do sinal.

Este processo é pouco usado atualmente.

\section{3- INDICAÇÃO DO IMPLANTE COCLEAR - CRITÉRIOS AUDIOLÓGICOS}

O paciente deve apresentar perda auditiva sensorioneural, severa ou profunda e bilateral de 90 $\mathrm{dB}$ ou maior em 500,1000, $2000 \mathrm{~Hz}$, expressa em decibéis $(\mathrm{dB})$ com referência aos limiares normais.

O candidato deve obter um resultado de $30 \%$ ou menor no teste de reconhecimento de sentenças sob melhores condições de ajuda com aparelho de amplificação sonora (AASI).

Deve-se lembrar que a plasticidade auditiva ocorre em maior grau com 1 ano de vida, daí a indicação de cirurgia em crianças implantadas abaixo de 12 meses, atualmente.

Crianças implantadas em uma idade mais jovem têm performance melhor. As crianças implanta- 
das abaixo de 2 anos atingem melhor performance no teste open-set de reconhecimento de fala.

Crianças com audição residual, muitas vezes, têm melhor performance com implantes. Aquelas com habilidade mensurável de reconhecimento de fala em open set, antes da implantação, realizam melhor performance.

Resumindo, os atuais critérios de seleção para implantação coclear pediátrica são:

- idade mínima de 12 meses, exceto em casos provados de ossificação coclear;

- perda auditiva sensorioneural bilateral severa a profunda;

- benefício do implante maior que o esperado por outros recursos;

- nenhuma contra-indicação clínica para anestesiageral;

- apoio familiar, motivação e expectativas adequadas;

- suporte de reabilitação para o desenvolvimento de linguagem oral, fala e audição.

\section{1- Contra-indicações absolutas:}

- agenesia da orelha interna (deformidade de Michel);

- ausência de nervo coclear;

- doença sistêmica que contra-indique anestesia ou cirurgia.

\section{4- EQUIPE DO IMPLANTE COCLEAR}

Um projeto de implante coclear deve ter como retaguarda uma equipe multidisciplinar que trabalhe com competência; cada um dando o melhor de si em sua área, visando um objetivo comum.

O fluxograma de atendimento e avaliação do candidato ao implante é o seguinte:

- a consulta é feita pelo otologista ou otorrinolaringologista que deve realizar o exame otorrinolaringológico completo, avaliar a possível causa da surdez, se é pré-lingual ou pós-lingual e solicitar os exames necessários para avaliação diagnóstica e exames complementares como tomografia computadorizada e imagem por ressonância magnética, para programar a cirurgia e constatar a estrutura normal da cóclea sem ossificação.

- O fonoaudiólogo receberá o paciente após a consulta do otologista realizando então a avaliação auditiva com os testes audiométricos convencionais. Deverá realizar os testes, com e sem AASI, da audição e reconhecimento da fala e linguagem, para ter idéia se o candidato tem os critérios para ser implantado e a possibilidade de audição ser ou não favorável.
- O assistente social - deverá avaliar as possibilidades financeiras da família e o nível cultural. É importante para possibilitar o uso de pilhas e o seguimento pós-operatório.

- O psicólogo deverá avaliar o estado emocional da família para verificar as suas expectativas, bem como, se dará suporte positivo para ajudar na reabilitação do implantado.

- O suporte de engenharia eletrônica e ciência da computação é importante para fornecer orientações técnicas sobre o dispositivo.

- O enfermeiro que cuidará do paciente no hospital, no seu pré- e pós-operatório é indispensável.

- Pedagogo e patologista da fala e linguagem (fonoaudiólogo) para realizar a reabilitação e treinamento.

Antes de passar ao estudo da avaliação do paciente, vamos tecer algumas considerações importantes:

Amplificação - a prótese auditiva (AASI) geralmente é insuficiente e não traz benefícios para a linguagem na surdez profunda e, nesses casos, com 12 anos as crianças abandonam a prótese (AASI).

A melhor prótese não amplifica mais que 40 dB. Quando a perda é de $90-95 \mathrm{~dB}$, a amplificação não atinge os $70 \mathrm{~dB}$ necessários para a criança ouvir.

\section{5- PlaStiCidAde E MATURAÇÃo AUdi- TIVA}

Pesquisas recentes revelam que o primeiro ano de vida é muito importante. A criança é capaz de discriminar fonemas de qualquer língua até 6 meses; após esta idade, discriminam fonemas somente do próprio idioma.

O máximo de aquisição de linguagem é de 2 a 3 meses; quanto mais cedo começar a estimulação, maior será o vocabulário.

\section{1- Desafio atual dos implantes}

Quanto mais nova a criança, maior a dificuldade de avaliação, cirurgia e reabilitação. Em adultos, estas etapas são mais fáceis de realizar.

Os testes nas crianças devem ser comportamentais e não elétricos. A mãe pode fazer testes com sua voz usando um medidor de pressão sonora. Pode também aprender a fazer o teste com videoteipe. $\mathrm{O}$ teste pode ser feito quando a criança adormece; quando a criança não responde, deve usar o aparelho de amplificação sonora individual (AASI). Se a criança não responde com essa prótese, a perda é profunda e o implante coclear deve ser indicado. 


\section{6- AVALIAÇÃO PRÉ-OPERATÓRIA}

A avaliação pré-operatória deve ser minuciosa. No exame médico, o paciente deve estar saudável. No exame otorrinolaringológico, o ouvido deve estar sem infecção. O exame audiológico deve ser feito com e sem AASI. No exame de fala e linguagem, a habilidade a estas funções da comunicação deve ser avaliada. No exame psicológico deve ser avaliado se a inteligência está dentro dos padrões normais e a estabilidade psicológica deve ser manifestada pelo paciente. Atualmente, o teste de estimulação do nervo não tem sido feito por grande número de autores. Ele visa verificar a integridade dos neurônios; pode ser utilizada a estimulação elétrica para tal fim.

A tomografia computadorizada , axial e coronal, dos ossos temporais é importante para conhecer a anatomia desses ossos e da cóclea, para o planejamento da cirurgia. Através dele podem ser excluídos anatomia anormal, trauma e infecção; deve-se avaliar se há aqueduto vestibular alargado (no plano axial); verificar se há artéria carótida aberrante; se o bulbo jugular é procidente na orelha média.

Deve ser detectada pelo C.T. a presença de malformação e a ossificação da cóclea (pós-meningite). Na imagem de ressonância magnética em $\mathrm{T}_{2}$ devese avaliar o nervo coclear, nervo vestibular, cóclea e canais semicirculares. A tomografia espiral deve ser realizada para a reconstrução tridimensional da cóclea (ossificação).

A motivação, cooperação do paciente e da família, se suas expectativas são realistas, devem ser constatadas. Neste caso, o médico e a equipe devem esclarecer que um implante pode não restaurar a audição normal, mas pode ajudar o paciente a se comunicar com mais facilidade e sentir-se mais ligado ao mundo que o rodeia.

\section{1- Seleção da orelha para o implante}

Em geral, quanto mais um ouvido implantado foi usado anteriormente, melhor o resultado da implantação. É preferível implantar uma orelha que tenha alguma audição residual e que fora usada com amplificação com AASI em passado recente.

\section{7- CIRURGIA}

A anestesia usada é a geral, sendo a cirurgia asséptica e uma variação da cirurgia do mastóide. A duração é de 2-3 horas. A incisão é retroauricular, de localização e forma variáveis. Na fresagem do mastóide, deve-se ter cuidados com o nervo facial. O monitoramento do facial deve ser feito principalmente na etapa de realização da timpanotomia posterior. Os cirurgiões usam, para crianças maiores e adultos, a técnica convencional que descreveremos resumidamente: (Figuras 3 a 10).

primeira etapa - mastoidectomia, com conservação da parede posterior do meato acústico externo (wall-up), para expor antro-ático e canal lateral com visualização da bigorna;

segunda etapa - realização de uma timpanotomia posterior para exposição da janela redonda e primeira espira da cóclea.

terceira etapa - fresagem do leito para fixarse o implante na parede óssea do crânio (nicho), atrás da apófise mastóidea.

quarta etapa - realização da cocleostomia entre a janela oval (estribo) e a janela redonda.

quinta etapa - colocação e fixação do receptor-estimulador no nicho.

sexta etapa - fechamento da incisão após ser realizada a telemetria neural intra-operatória para avaliar as condições dos eletrodos inseridos na cóclea.

Esta técnica é a de mastoidectomia com timpanostomia posterior.

Na nossa experiência para realização da cirurgia, o grupo de cirurgiões (4) participa da maioria das cirurgias revezando-se na realização das diferentes etapas citadas. Este procedimento traz várias vantagens para a realização do projeto do implante coclear.

Técnica da cirurgia microinvasiva - é a cirurgia realizada no grupo pediátrico que requer atenção na alta incidência de estruturas anômalas. O nervo facial exteriorizado do osso temporal pelo forame estilomastóideo. Os tecidos são delicados devendo-se evitar manipulação da pele.

Há muita semelhança com a técnica convencional descrita acima e utilizada para adultos. Algumas diferenças são: incisão pequena de 3 a $4 \mathrm{~cm}$, retroauricular, feita em linha reta; cuidados com a manipulação dos retalhos que, em crianças, são mais delicados; descolamento de um retalho completo de tecido até o periósteo elevando-o para formar uma bolsa, onde será fresado o leito do implante que deverá, na maioria das vezes, atingir a dura-máter devido a menor espessura da parede óssea craniana. A fresagem deve ser cuidadosa para não deixar toda a duramater exposta. Deve-se deixar uma placa óssea circular central onde será colocado o implante coclear. 


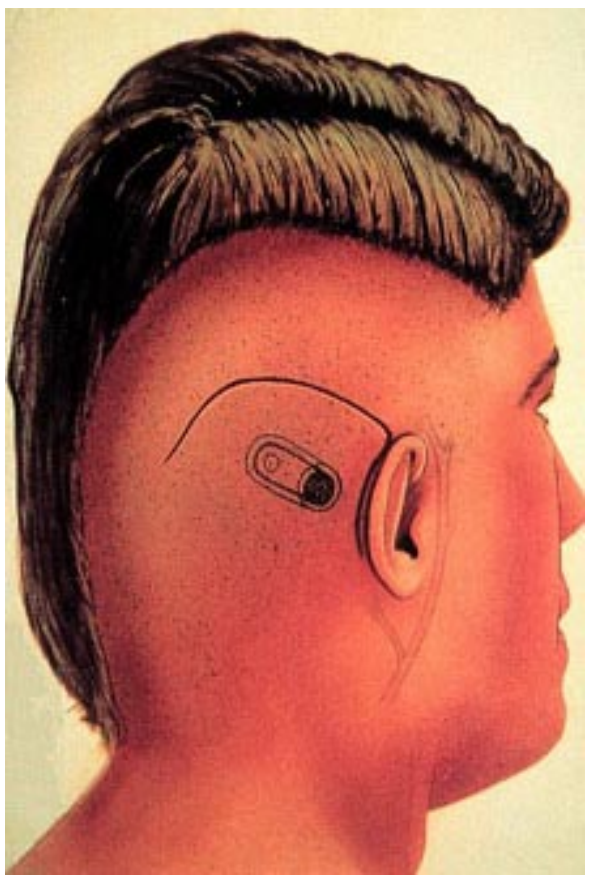

Figura 3 - Incisão e local da posição do implante.

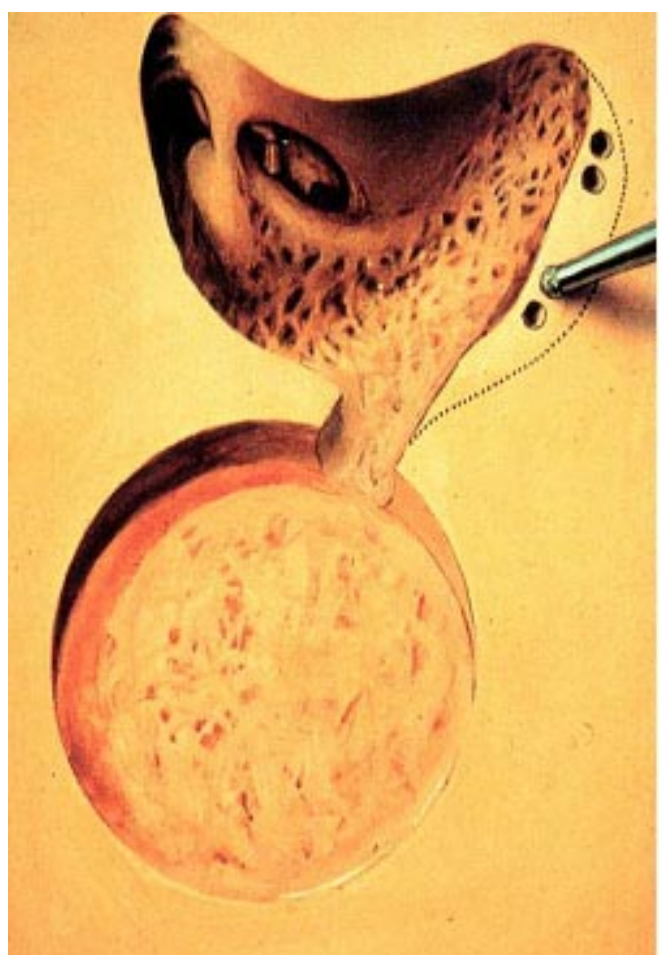

Figura 5 - Mastoidectomia, timpanostomia posterior e leito do implante.

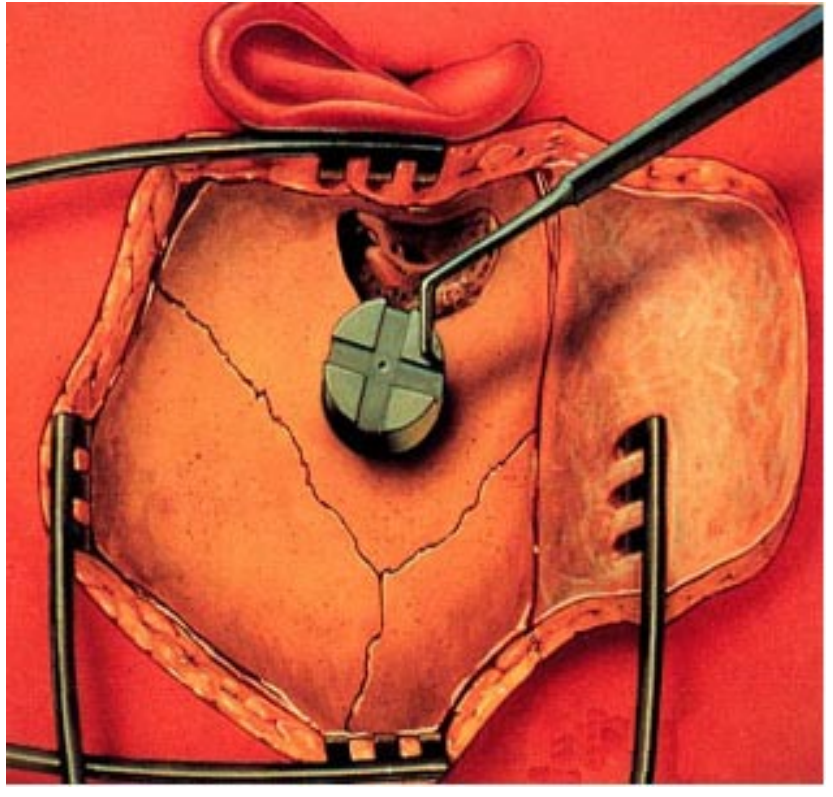

Figura 4 - Mastoidectomia realizada. Uso de modelo do implante para preparação do leito do implante.

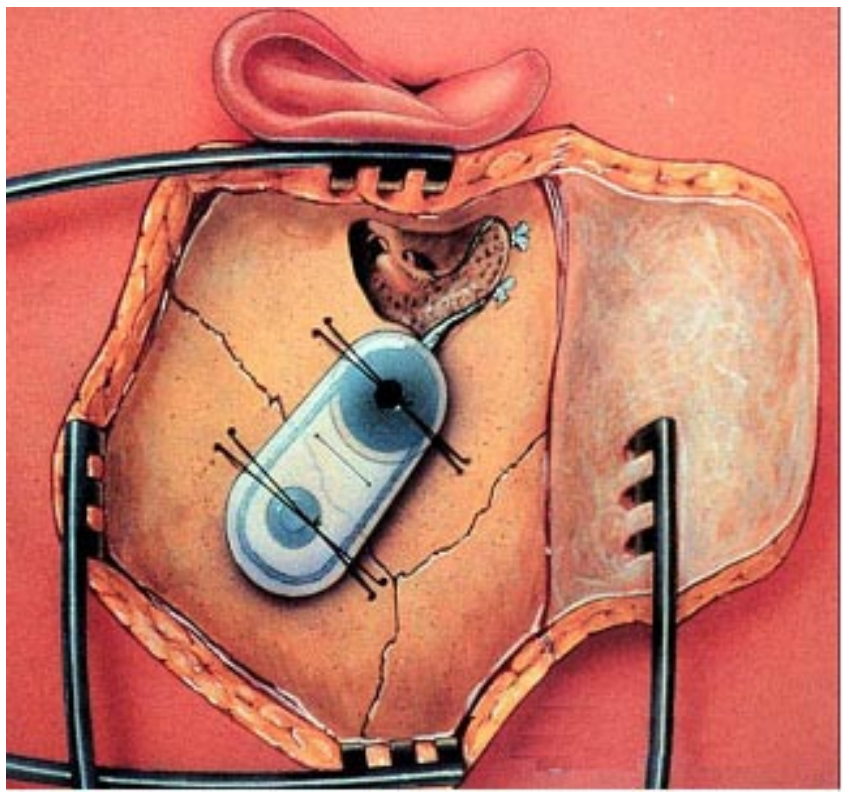

Figura 6 - Implante fixado no leito fresado do osso temporal. 


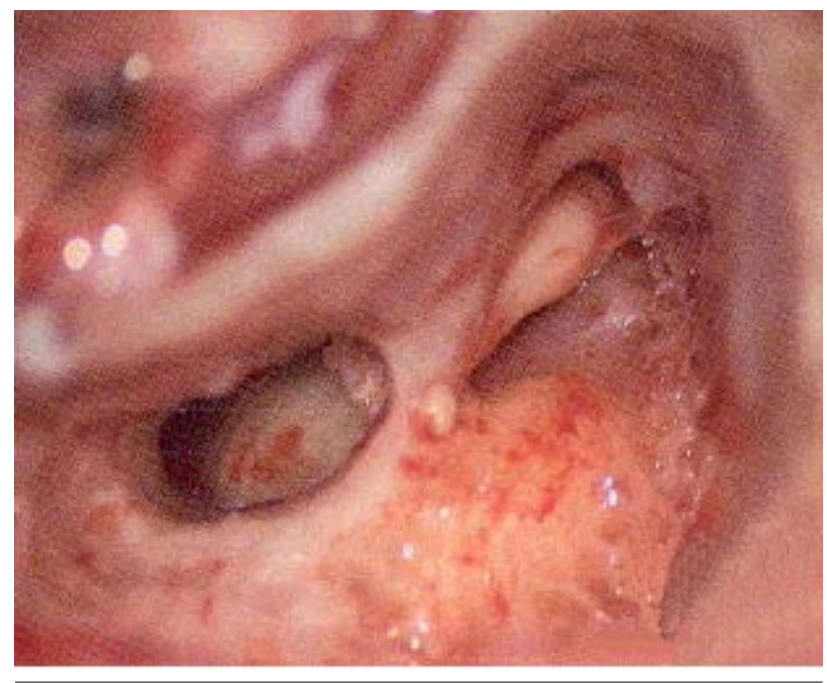

Figura 7 - Antroaticotomia expondo o canal semicircular lateral e o corpo da bigorna. (Modificado do original: Mondain M, Gresillon N, Romdhane S, Sillon M, Vieu A, Geffriaud G et al. Les implants cichl'eaires chez l'enfant et l'adulte sourd profonde ou sévère. In: Casenave A, Mondain M, Frachet B, Hamann C, Sterkes O, éditeurs. Les surdités de la prothèse à l'implant. France: GE; 2002. p 78).

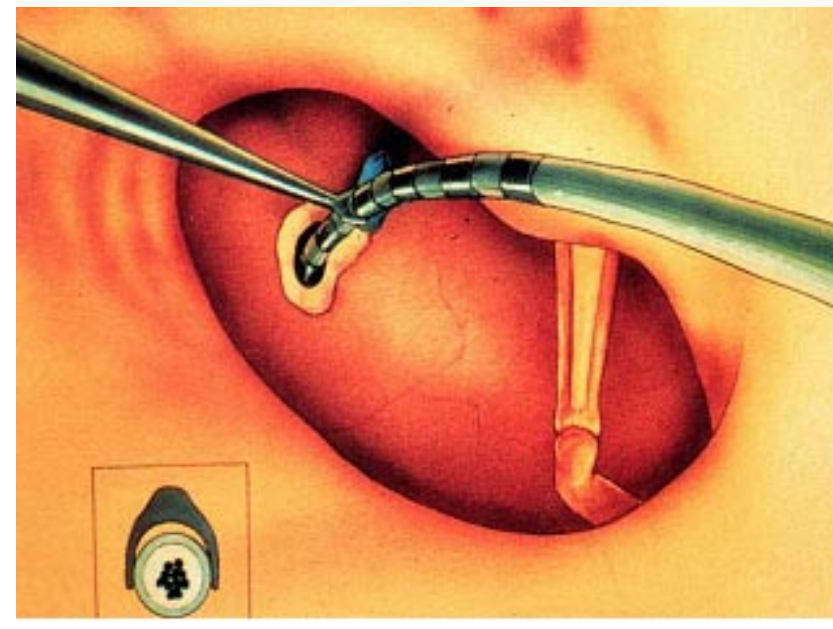

Figura 9 - Esquema da timpanotomia posterior mostrando os eletrodos sendo introduzidos no interior da cóclea.

\section{1- Etapas cirúrgicas}

a) a incisão usada é de 3-4 cm, retroauricular e em linha reta; distante $1 \mathrm{~cm}$ do sulco retroauricular. Após a incisão, os bordos são separados com afastadores, clipes ou ganchos;

b) é feito um flap periostal com base anterior e descolado para formar uma bolsa para o dispositivo eletrônico (I.C.);

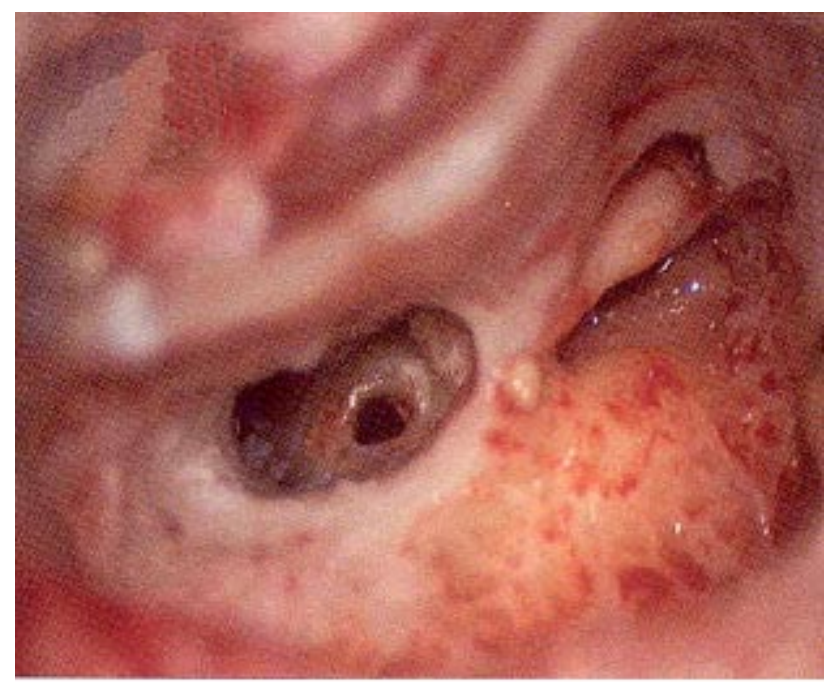

Figura 8 - Cocleostomia na primeira espira da cóclea, entre o estribo e a janela redonda. (Modificado do original Mondain M, Gresillon N, Romdhane S, Sillon M, Vieu A, Geffriaud G et al. Les implants cichl'eaires chez l'enfant et l'adulte sourd profonde ou sévère. In: Casenave A, Mondain M, Frachet B, Hamann C, Sterkes $\mathrm{O}$, éditeurs. Les surdités de la prothèse à l'implant. France: $\mathrm{GE}$; 2002. $p$ 78.).

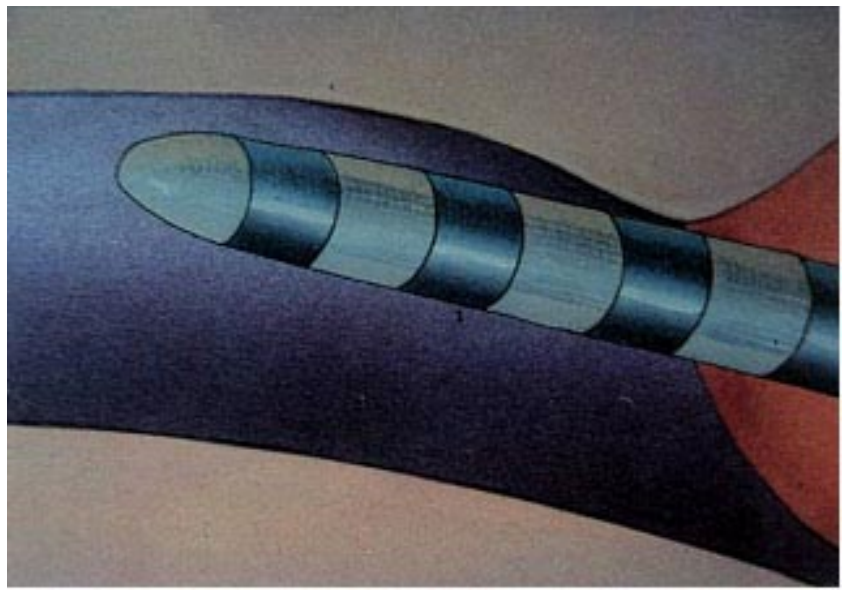

Figura 10 - Eletrodos penetrando nas espiras cocleares, rodeando o modíolo.

c) o lugar do dispositivo eletrônico é identificado com modelo do implante sendo, na criança, suficientemente posterior à fresagem do leito do implante para permitir o uso do pacote eletrônico. Após o uso do modelo e identificação do lugar, este é fresado. Em crianças muito jovens pode ser necessário colocar o receptor-estimulador diretamente sobre um plano fino de osso (casca de ovo) sobre a dura-máter; 
d) a mastoidectomia completa, timpanotomia posterior e cocleostomia são realizadas. O conjunto de eletrodos é inserido na escala timpânica através da cocleostomia;

e) a abertura da cocleostomia é tamponada com músculo ou fascia e o receptor-estimulador é depositado na bolsa formada inicialmente. $\mathrm{O}$ flap é suturado e fechado sobre o dispositivo.

Visita pós-operatória na $1^{\mathrm{a}}$ semana para avaliar a cicatrização. Em seguida, visita em 2 a 3 semanas para ajuste do mapeamento da atividade do processador de fala.

Uma grande diferença da técnica minimamente invasiva é que o implante é colocado sem fixação ao osso através de pontos. A bolsa feita inicialmente deve ser pequena o bastante para prender o enxerto no lugar, após sutura da incisão.

\section{2- Complicações cirúrgicas}

A cirurgia deve ser realizada por cirurgiões otológicos, com prática em mastoidectomias. Há risco de lesão do nervo facial por isso deve-se realizar a cirurgia com monitoramento do nervo. Outros riscos são a formação de uma fístula labiríntica permanente; lesão da corda do tímpano, com perda da sensibilidade gustativa por vários meses; lesão do anel e membrana timpânicos; lesão do seio sigmóide; lesão da dura-máter. As complicações cirúrgicas são pouco freqüentes quando os cirurgiões são experientes.

\section{3- Complicações pós-operatórias}

Podem ocorrer problemas com os retalhos provocando infecção, hematoma, necrose. O eletrodo pode ficar em posição incorreta e, devido a isso, pode estimular o nervo facial. Podem ocorrer fístula liquórica no nicho do receptor e fístula perilinfática. Outras complicações pós-operatórias são otite média aguda, otite média crônica, meningite, fratura do receptor, migração do eletrodo, extrusão do receptor ou interrupção do funcionamento, dor. Estas complicações são pouco freqüentes.

Os cuidados pós-operatórios principais são: evitar banhos de piscina; evitar esportes com riscos de trauma na cabeça; realização de otoscopia de controle.

\section{8-ASPECTOS CLÍNICOS DA IMPLANTAÇÃO COCLEAR: AVALIAÇÃO DETALHADA}

Treino e reabilitação - na surdez profunda, o implante é uma oportunidade única de compreender a fala e escutar sons do ambiente.
Surdez profunda pós-lingual - é quando o indivíduo nasce com audição e aprende a falar antes de adquirir a surdez. Nesse caso, os pacientes implantados têm melhor prognóstico.

Surdez profunda pré-lingual - é quando o indivíduo torna-se surdo precocemente, na infância, antes de aprender a falar.

Em ambos tipos de surdez profunda, quanto mais recente a perda da audição, mais fácil será a interpretação de sinais liberados por um implante coclear.

\section{1- Reabilitação do implantado}

Ativação do implante - após a ativação do implante, o paciente recebe uma variedade de sons, incluindo os sons da fala. No início os sons estão distorcidos, não parecendo familiar ao paciente.

Aprender a interpretar os sinais do implante é como aprender uma língua estrangeira, exige tempo e prática, principalmente para quem é surdo há muito tempo ou nunca ouviu.

O cérebro aprende gradualmente o significado dos impulsos elétricos e depois o significado das mensagens sonoras.

O paciente implantado começa a compreender alguma fala e os sons parecem mais naturais. O implantado deve retornar à clínica de reabilitação para sessões de treinamento específico com fonoaudiólogo.

O treinamento de reabilitação é essencial para o êxito na performance do paciente implantado. Esse treino é para desenvolver audição e leitura de fala.

O paciente pode realizar o treinamento em casa, com retornos para orientação dos fonoaudiólogos.

\section{2- Avaliação da performance}

Avaliar no implantado a capacidade de identificar e reconhecer a fala. Nos testes utilizam-se palavras monossílabas, vogais, consoantes e sentenças. Os melhores resultados são nos testes com sentenças. Esses testes podem exigir alto nível de conhecimento de gramática, contexto e semântica, no reconhecimento das palavras nas sentenças. Um exemplo é o preenchimento das sentenças com palavras.

Nos testes open set com sentenças, os pacientes não sabem a lista de todas escolhas de palavras possíveis. Os testes close set são aqueles com vogais e consoantes; neles, o paciente sabe todas as escolhas possíveis. Esses testes não são necessariamente mais fáceis porque todos os itens da lista são foneticamente semelhantes. O objetivo desses testes é avaliar a habilidade do paciente em resolver informação espectral e temporal. 


\section{3- Performance auditiva}

É a capacidade de discriminar, detectar, identificar ou reconhecer a fala.

O resultado é medido pelo escore obtido, em porcentagem, em testes de reconhecimento da fala com sentenças (open set).

\section{Fatores que afetam a performance auditiva}

duração da surdez - tem efeito negativo forte. Quando a deprivação da estimulação auditiva é mais curta, o resultado é melhor;

idade de início da surdez - a surdez sendo pré-lingual a performance é pior. Adultos e crianças pós-linguais têm melhor performance auditiva do que crianças com surdez congênita;

idade da implantação - surdos pré-linguais implantados na adolescência têm melhor performance auditiva do que adultos implantados pré-linguais.

Crianças implantadas em idades precoces têm melhor performance que na idade adulta.

Hoje, sabe-se que quanto mais precoce a implantação, melhores serão os resultados. No congresso internacional realizado em 2005, em Dallas (EUA), o consenso foi de que a melhor época para implantação é aos 12 meses.

Duração do uso do implante - tem efeito positivo na performance auditiva para adultos e crianças.

Outros fatores que podem afetar o desempenho auditivo para adultos e crianças são o número de células ganglionares remanescentes na cóclea; colocação correta do eletrodo e a profundidade de inserção possibilitando a estimulação dos sons agudos na base e graves no ápice; faixa dinâmico-elétrica; estratégia de processamento de sinal; nível de inteligência do paciente; comunicabilidade.

\section{9- CAPACIDADE DE PERCEPÇÃO DA FALA EM CRIANÇAS IMPLANTADAS}

Esta capacidade aumenta com o tempo, para crianças com surdez pré-lingual, em um período de 3 ou 4 anos.

Em crianças implantadas com surdez pós-lingual, a melhora da percepção da fala é rápida nos primeiros 6 meses e tem melhores resultados nos testes open set comparados com crianças com surdez pré-lingual.

No congresso internacional de implante coclear em crianças (Dallas, US - 2005) houve consenso em considerar que as crianças implantadas com 12 me- ses têm a evolução de sua audição e fala como a de uma criança ouvinte.

A criança de 1 ou 2 anos tem a necessidade de desenvolver linguagem falada, sendo a idade crucial para o desenvolvimento da linguagem e capacidade cognitiva.

A implantação coclear possibilita que a criança adquira habilidade de falar claramente e desenvolver capacidade de percepção e compreensão da fala. Isto ocorre porque a habilidade de fala na criança está relacionada à capacidade de ouvir. A criança com deficiência auditiva tem dificuldade de falar corretamente. A audição fornece feed-back que é usado para regular e corrigir sua produção de fala.

\section{1- Objetivos do implante coclear}

- permitir ao paciente alcançar a capacidade de compreensão da fala nos testes open set somente com a audição, ou seja, ser capaz de escutar e compreender a fala usando apenas o implante, sem qualquer pista visual (leitura labial).

- aumento da leitura labial - com isso o paciente obtém maior informação sobre duração; sensação de freqüência ( pitch); sensação de intensidade (loudness); inflexão e modulação da voz (>90\%).

- ligação com o mundo através dos sons ambientais, sociabilidade, independência.

\section{0- CONSIDERAÇÕES SOBRE IMPLANTA- ÇÃO COCLEẢR PEDIÁTRICA}

\section{1- Avaliação do candidato}

Deve ser feita avaliação clínica, estado de saúde do paciente, possibilidade de sofrer anestesia geral, estresse físico, na história médica. Exames laboratoriais, estudo de imagens, exame oftalmológico (alterações visuais) em crianças surdas. Avaliação médica cardiológica, pesquisa de história familiar de morte súbita cardíaca na família. Requisitar, no caso, o eletrocardiograma para avaliar anormalidade associadas com a síndrome de Jervell-Lange-Nielson. Avaliação de doenças sistêmicas; auto-imunes; diabete melito; doentes imunodeprimidos após transplante de órgãos. Todos esses podem ser implantados, após avaliação cuidadosa, se estiverem controlados. Avaliação por imagem é realizada como no adulto, por tomografia computadorizada, para avaliar pneumatização da mastóide, espessura do osso parietal na área do implante, localização do nervo facial, do recesso do facial, anatomia e ossificação da cóclea, localização da jane- 
la redonda, anatomia vascular (carótida, seio sigmóide e vias emissárias). Anormalidades cocleares e malformações devem ser identificadas no pré-operatório. A imagem de ressonância magnética também é muito importante.

No caso de paciente pediátrico, a avaliação da expectativa dos pais, da condição social da família, a performance com o uso de AASI e adesão da terapia são aspectos importantes da avaliação da criança.

\section{2- Sucesso do implante na criança}

Para o implante coclear ter o máximo sucesso, a educação com comunicação auditiva oral, tradicional ou total, deve ser feita com ênfase na comunicação oral e desenvolvimento auditivo.

A longo termo, o grau de sucesso na habilitação depende mais da idade precoce da criança implantada do que do tipo de implante. Outro fator importante é a criança participar de uma terapia auditiva forte, com base na oralidade e centrada na família. Nesse caso, há benefício máximo na percepção da fala e desenvolvimento da linguagem.

A habilitação a longo termo continua essencial para crianças após a implantação coclear. O grau de sucesso alcançado na criança está relacionado com a idade de implantação e uso efetivo de habilitação auditiva. $\mathrm{O}$ treinamento precoce em linguagem de sinais está associado com melhoras lingüísticas pobres.

Os resultados têm mostrado melhora na performance nos últimos 2 anos. Crianças mais jovens implantadas têm melhor desempenho. Crianças maiores de 5 anos beneficiam-se mais do que com AASI, entretanto, menos do que as crianças com implante coclear em idade menor.

Na maioria das crianças, o implante coclear e terapia oral promovem desenvolvimento da linguagem falada, além daquele possível de ser alcançado com AASI.

Crianças implantadas aos 12 meses aprendem linguagem na mesma velocidade de crianças ouvinte de idade similar.

\section{1- POSSIBILIDADE FUTURA DE IMPLAN- TE COCLEAR}

Vários desenvolvimentos tecnológicos serão usados nos próximos anos:

- implantação coclear binaural já tem sido usada em crianças, havendo vantagens de menos interação entre canais, aumento da audição no ruído e localização dos sons;
- uso de eletrodo perimodiolar (maior contato com o modíolo);

- criação de baterias recarregáveis que resolveria o problema do alto custo da pilha pois ela dura pouco tempo;

- implantação de crianças e adultos com audição residual para preservação dos elementos neurais existentes;

- estimulador eletroacústico híbrido, com eletrodo curto, atraumático, acoplado a um AASI implantado. As perdas de severas a profundas de tons agudos são tratadas eletricamente e perdas leves a moderadas são tratadas acusticamente;

- neurotrofinas no implante - estudos procuram obter preservação neural utilizando em associação com o implante, neurotrofinas, técnicas genéticas moleculares e bloqueadores de vias de apoptose liberados pré-operatoriamente ou através dos eletrodos dos implantes cocleares.

Nova tecnologia permite escutar através do microfone do implante coclear, de modo a testar a qualidade do som e alarmes audíveis como o de baterias descarregadas. Medidas de telemetria ultra-rápida intra-operatória provêm segurança de que não existe nenhum curto-circuito nos eletrodos e que o dispositivo está funcionando.

Papel da telemetria neural - programa objetivo na reabilitação pode ser realizado pela telemetria intra-operatória como parte da programação para confirmar a estimulação auditiva.

Essa avaliação pela telemetria de resposta neural NTM) é um ponto inicial para programação comportamental.

O objetivo do programa é medir o potencial de ação global do nervo acústico evocado eletricamente por telemetria de resposta neural (RTN). Essa medida não requer eletrodos externos, sendo determinada diretamente através do sistema do implante.

As respostas NRT para confirmar a estimulação auditiva podem ser usadas como um ponto inicial para o programa comportamental.

Reflexo acústico - é outra medida importante, objetiva e útil na programação da criança. O reflexo muscular da orelha média produzido eletricamente é uma forma de reflexo acústico ou estapediano provocado através do implante coclear. Isso correlacionase com estimulação em nível máximo desejado.

Respostas elétricas evocadas de tronco cerebral (ABR) - as ondas do ABR podem ser registradas intra ou pós-operativamente em pacientes cooperativos podendo ser usadas de modo similar a RTN. 
OLIVEIRA JAA. Cochlear implant. Medicina (Ribeirão Preto) 2005, 38 (3/4): 262-272.

ABSTRACT: Cochlear implant surgery is currently the only effective treatment in cases of bilateral profound deafness in children and adults. It is important to diagnose sensorineural deafness using a battery of specialized exams conducted by a multidisciplinary team. After this evaluation, on the basis of the result obtained and of the criteria of implant indication, the patient is selected for implantation surgery. The objective of the present review was to focus on the current status of the treatment of bilateral profound sensorineural deafness by cochlear implant surgery.

Key words: Cochlear Implants. Hearing Loss, Sensorineural. Ear, Internal. Labyrinth.

\section{AGRADECIMENTO}

À Maria Helena de Andrade, biologista do Setor de Otorrinolaringologia (HCFMRP-USP) pela digitação e revisão do texto e edição das imagens usadas neste trabalho.

\section{LEITURA RECOMENDADA}

1 - Balkany TJ, Hodges AV, Eshraghi AA, Butts S, Bricker K, Linguai J, Polak M, King J. Cochlear implant in children - a review. Acta Otolaryngol 2002; 122: 356-62.

2 - Blamey P, Arndt P, Bergeron F, Bredberg G, Brimacombe J, Facer G, Larky J, Lindstrom B, Nedzelski J, Peterson A, Shipp D, Staller S, Whitford L. Factors affecting auditory performance of postlinguistically deaf adults using cochlear implants. Audiol Neurootol 1996; 1: 293-306.

3 - Clark G, Shepherd R, Patrick J, Black R, Teng Y. Design and fabrication of the banded electrode array. Ann N Y Acad Sci 1983; 405:191-201.

4 - Dolan S, Hodges A, Butts S, Balkany T. Borderline pediatric cochlear implant candidates: preoperative and postoperetive results. Ann Otol Rhinol Laryngol 2000; 185 (Suppl):36-8.

5 - Dorman M, Loizou P, Rainey D. Simulation the effect of cochlear implant electrode insertion- depth on speech understanging. J Acoust Soc Am 1997; 102: 2993-6.

6 - Gantz B, Woodworth G, Abbas P, Knutson J, Tyler R. Multivariate predictors of audiological success with multichannel cochlear implants. Ann Otol Rhinol Laryngol 1993; 102: 90916.

7 - Goycoolea MV, Ribalta G. Exploratory timpanotomy: an integral part of cochlear implantation. Acta Otolaryngol 2003; 123: 223-6.

8 - Hinojosa R, Marion M. Histopathology of profound sensorioneural deafness. Ann N Y Acad Sci 1983; 405: 45984.
9 - Hochmair-Desoyer I, Hochmair E, Burian K. Design and fabrication of multiwire scala tympani electrodes. Ann N Y Acad Sci 1983; 405: 173-82.

10 - Hodges AV, Balkany TJ, Ruth RA, Lambert PR, Dolan-Ash S, Scholoffman JJ. Electrical middle ear muscle reflex: use in cochlear implant programming. Otolaryngol Head Neck Surg 1997; 117: 255-61.

11 - Loizou PC. Introduction to cochlear implants. IEEE Eng Med Biol 1999; 18: 32-42.

12 - Migirov L, Yakirevitch A, Kronemberg J. Medical and surgical complication following $\mathrm{Cl}$ : comparison of two surgical approaches. $10^{\text {th }}$ Symposium on Cochlear Implants in Children, Dallas-Te; 2005. p.18.

13 - Shallop JK, Peterson A. Neural response telemetry with Nucleus C124M cochclear implant. Laryngoscope 1999; 109: 1755-9.

14 - Summerfield A, Marshall D. Preoperative predictors of outcomes from cochlear implants in adults: performance and quality of life. Ann Otol Rhinol Laryngol 1995; 166 (Suppl): 105-8.

15 - Tobey E. Speech Production. In: Tyler R, ed. Cochlear Implants: Audiological Foundations. New York: Singular Publishing Group Inc;1993. p.257-316.

16 - Tyler R. Speech perception by children. In: Tyler R, ed. Cochlear Implants: Audiological Foundations. New York: Singular Publishing Group Inc;1993. p.191-256.

17 - Waltzman SB, Cohen NL. Cochlear implantation in children younger than 2 years-old. Am J Otol 1998; 19: 158-62.

18 - Wilson B, Lawson D, Zerbi M. Advances in coding strategies for cochlear implants. Otolaryngo Head Neck Surg 1995; 9:105-29.

19 - Zwolen TA, Zimmerman-Phillips S, Ashbaugh CJ, Hieber SJ, Kileny PR, Telian SA. Cochlear implantation of children with minimal open set speech recognition skills. Ear Hear 1997; $18: 240-51$. 